\title{
A LETALIDADE EM AÇÕES POLICIAIS \\ Uma revisão do debate a partir da análise comparativa entre as polícias dos Estados do Rio de Janeiro e São Paulo
}

\section{LETHALITY IN POLICE ACTIONS \\ A review of the debate based on a comparative analysis between the police in the states of Rio de Janeiro and São Paulo}

\author{
Luís Antônio Francisco de Souza \\ Universidade Estadual Paulista, Departamento de Sociologia e Antropologia e Programa de Pós-Graduação em \\ Ciências Sociais. Av. Hygino Muzzi Filho, 737, - Mirante, Marília - SP, Brasil, CEP 17525-900. \\ Email: lafraso@hotmail.com
}

\begin{abstract}
Carlos Henrique Aguiar Serra
Universidade Federal Fluminense, Departamento de Ciência Política e Programa de Pós-Graduação em Ciência Política. Campus do Gragoatá - Rua Professor Marcos Waldemar de Freitas Reis, Bloco O, Rio de Janeiro - RJ, Brasil, CEP 24210-201. Email: chaserra@id.uff.br
\end{abstract}

\section{Marcial A. Garcia Suarez}

Universidade Federal Fluminense, Departamento de Ciência Política e Programa de Pós-Graduação em Ciência Política. Campus do Gragoatá - Rua Professor Marcos Waldemar de Freitas Reis, Bloco O, Rio de Janeiro - RJ, Brasil, CEP 24210-201. Email: marcialgsuarez@gmail.com

\section{Gabriel de Sousa Romero}

Universidade Federal de São Paulo, R. Sena Madureira, 1500 - Vila Clementino, São Paulo - SP, Brasil, CEP 04021-001. Email: doromero@gmail.com.

Resumo: A persistência de altos níveis de letalidade em ações da polícia constitui um dos grandes desafios da democracia no Brasil contemporâneo. Desde o processo de redemocratização, nos anos 1980 a 1990, a letalidade e a violência policiais têm se colocado no cerne do debate em torno da segurança pública. Iniciativas de controle surgiram nas duas últimas décadas. Estudos mostraram as múltiplas faces e dimensões do problema, mas políticas efetivas de controle da violência policial não foram implantadas até o presente momento. O presente artigo propõe uma análise comparada da letalidade policial a partir da experiência das polícias dos Estados do Rio de Janeiro e de São Paulo e explorando a influência desta letalidade sobre a taxa de homicídios. Por fim, propomos um debate por meio de uma revisão dos estudos sobre o tema, sinalizamos possibilidades de compreensão da persistência da violência policial, bem como perspectivas em torno do seu controle.

Palavras-chave: letalidade, violência policial, Rio de Janeiro, São Paulo.

\begin{abstract}
The persistence of high levels of lethality in police actions is one of the great challenges of democracy in contemporary Brazil. Since the process of redemocratization in the 1980s and 1990s, police lethality and violence have been at the heart of the debate around public security. Control initiatives have emerged in the past two decades. Studies have shown the multiple features and dimensions of the problem, but effective policies to control police violence are yet to be implemented. This article presents a comparative analysis of police lethality based on polices' experiences in the states of Rio de Janeiro and São Paulo. It further explores the influence of this lethality on homicide rates. Finally, we discuss our data taking into account previous studies on this topic, point out possibilities
\end{abstract}


for understanding the persistence of police violence, as well as perspectives around its control.

Keywords: lethality, police violence, Rio de Janeiro, São Paulo

\section{Introdução}

No Brasil, as pesquisas acadêmicas enfocando problemas relativos ao funcionamento das instituições jurídico-policiais datam de no máximo 25 anos. Até metade da década de 1970, pouquíssimos pesquisadores se interessaram pelo campo das práticas policiais. $\mathrm{O}$ interesse acadêmico estava voltado para as estruturas institucionais de repressão da ditadura militar (Battibugli, 2007; Moraes, 1996; Pinheiro, 1991). Durante a década de 1980, a Polícia Militar começou a se tornar centro das discussões em torno da necessidade de reformas institucionais (Lima, 1989, 1995; Mingardi, 1992). Naquela ocasião, a violência policial era parte de discussão mais ampla sobre o modelo de polícia a ser adotado na Constituição Federal (CF) de 1988. Com o processo de redemocratização, um novo quadro institucional passou a ser construído, todavia as polícias exerceram resistência às mudanças exigidas pela nova ordem constitucional. Desta forma, o modelo policial legado pela ditadura militar de 1964-1985 permaneceu praticamente inalterado.

Os estudos realizados apontam para duas explicações sobre a persistência da violência policial no contexto democrático. Por parte do governo e da polícia, a brutalidade policial é consequência do confronto direto contra os criminosos e, ao mesmo tempo, indicativo de uma formação insuficiente dos policiais em relação aos conflitos urbanos armados. Por parte dos pesquisadores provenientes do ambiente acadêmico, a violência assim como a corrupção, são legados da ditadura, já que a democracia não havia promovido mudanças substantivas no aparato policial. Mais do que isto, a violência policial é parte integrante do quadro de incapacidade do Estado Brasileiro de exercer o monopólio da força legítima (Adorno, 2002; Caldeira, 2001; Mesquita Neto, 1999; Moraes, 1996; Pinheiro, 1991; Soares, 2000). O debate sobre a letalidade em ações policiais ganhou renovado interesse nos anos 2000 (Belli, 2004; Bicudo, 2000; Souza \& Battibugli, 2014).

Uma das características marcantes das polícias que matam no Brasil é o militarismo. A redemocratização não desmilitarizou as polícias. Mais do que isto, os discursos e as estratégias policiais sempre emergem de concepções militarizadas. Sendo assim, as polícias "combatem" o crime, "eliminam" o criminoso, "derrotam" o tráfico de drogas, "confrontam" o inimigo, "ocupam" o território, realizam "intervenções" nas favelas e morros (Battibugli, 2007; Borges, 2003; Souza, Serra \& Battibugli, 2019; Stepan, 1975; Stephan, 2016). 
Estas estratégias são persistentes na história da polícia no Brasil e são legitimadas todas as vezes que a polícia mata. Embora o Programa Nacional de Segurança Pública com Cidadania (Pronasci) ${ }^{1}$, lançado em 2007, em consonância ao Plano Nacional de Segurança Pública propunha um conjunto de ações de defesa e aprimoramento dos direitos humanos de cidadania, o caráter militar das polícias não foi enfrentado (Cristino, 2008; Fontoura, Rivero \& Rodrigues, 2009, p. 171).

Ao contrário, o governo federal optou por regulamentar a utilização direta das Forças Armadas na segurança pública, como atribuição subsidiária em Operações de Garantia da Lei e da Ordem (GLO)². Sendo assim, o principal plano de segurança do país continha uma ambiguidade fundamental. As forças policiais militarizadas oscilam entre "combater" a criminalidade utilizando a força e promover cidadania 3 . A ambiguidade foi desfeita no governo Michel Temer (2016-2018), que adotou, na segurança pública, a estratégia da lei e da ordem, com reforço de operações e de intervenções militares nos Estados, sobretudo no Rio de Janeiro (Almeida, 2014). Isto pode ser visto no fortalecimento do caráter militarizado das ações de segurança da Copa do Mundo de 2014 e das Olimpíadas de 2016. O plano de segurança pública do Governo Temer, de 2017, reforça ainda mais esta tendência (Almeida, 2014, p. 61; Estevam, 2010; Gusso, 2013; Souza, 2012).

Reiterou-se, portanto, a partir de 2015, o modelo militarizado de segurança pública. Dessa forma, o processo de agenda setting para o setor continua a ser um misto de interesses políticos, corporativos e militares (Bayley, 2001; Fontoura et al., 2009; Lima, 1995). Esta tendência pode ser observada nas guardas municipais. Os municípios desde a CF de 1988 passaram a ter prerrogativa de criar suas guardas policiais. Desde então várias cidades brasileiras vêm formando seus pequenos exércitos de policiais armados, muitos dos quais auxiliam em funções complementares de combate ao crime (Sento-Sé, 2005).

Ao analisarmos de maneira mais aproximada se percebe que a requisição das Forças Armadas para ações policiais via o instituto da Garantia da Lei e da Ordem, mais do que um fenômeno extemporâneo, ao contrário, se trata de um expediente recorrente e corriqueiro na política de segurança pública brasileira. Entre 1992 e 2020, ou seja, num intervalo de 28 anos foram instituídas 142 situações nas quais as Forças Armadas foram demandadas pelos poderes constitucionais para intervir em assuntos distintos a Defesa stricto sensu. Se fizermos uma simples mediana isto indica que as Forças Armadas são chamadas para diferentes ações quase cinco vezes por ano.

Por outro lado, ao visualizarmos a natureza destas ações, a questão da militarização da segurança pública se torna mais evidente ainda. Se somarmos os eventos que estão diretamente ligados a segurança pública e que são decorrentes da fragilidade dos órgãos responsáveis por esta, se pode visualizar que em 35,3\%. Sendo assim, as Forças 
Armadas podem realizar atividades policiais como revistar pessoas, veículos, embarcações, bem como podem deter pessoas consideradas suspeitas em áreas de fronteira. Forças militares brasileiras desempenharam papel na estabilização social e política do Haiti.

A segurança de grandes eventos internacionais depende do planejamento e da presença ostensiva das Forças Armadas. A Força Nacional de Segurança (FNS) tem assumido papel de polícia permanente em vários Estados brasileiros. Oficiais das forças militares têm presença significativa nas agências de inteligência e nas instituições da segurança, assim como policiais militares têm presença garantida em diferentes instâncias da administração pública ${ }^{4}$.

A política de ocupação dos territórios dominados pelo tráfico e a implantação das Unidades de Polícia Pacificadora (UPP) respondem à demanda pela militarização do campo social, bem como a Lei antiterrorismo de 2016 (Lei n ${ }^{\circ} 13.260$ ), que ao reformular o conceito de organização terrorista amplia as margens do poder do Estado sobre as populações, movimentos e ações consideradas de alto risco para a segurança do país (Fleury, 2012). Por último, a tendência de militarização apresenta fortemente consolidada nas polícias militares (PM), já que estas continuam subordinadas ao Exército Brasileiro. O efetivo de policiais armados vem crescendo acompanhando a pressão midiática por mais segurança e, por que não dizer, acompanhando de perto o crescimento exponencial do mercado privado de segurança. Os crimes cometidos pelos policiais militares, em funções de policiamento, ainda são definidos como crimes militares e, portanto, como transgressões disciplinares, submetidas a um código, a um processo e a uma justiça militar próprios (Aguilar, 2012; Zaverucha, 2005, 2010).

Os mandatos da polícia e das Forças Armadas também são diferentes. A primeira articula prevenção e repressão ao crime, assim como a gestão dos conflitos que emergem do cenário social. Trata-se de um mandato civil para períodos de paz. As Forças Armadas (FA), de outra forma, têm como mandato a garantia da soberania territorial contra a intervenção e a ameaça externa. Na doutrina, polícia e exército detêm o monopólio estatal da força física por meio do uso autorizado e legal da arma. Embora a autorização para o uso da força seja característica fundadora destas duas instituições, é importante ressaltar que a polícia é caracterizada pelo uso controlado e progressivo da força, enquanto o exército preconiza o uso da arma como instrumento dissuasório por excelência. Além do mais, a doutrina, armamento, instrução e treinamento da polícia e do exército são distintos em razão dos mandatos diferentes. Em termos de concepção e de prática, as táticas de guerra permitem estabelecer um corte preciso entre polícia e exército (Bayley, 2006; Bittner, 2003; Dieu, 1993; Ericson \& Haggerty, 1997; Waddington, 1999).

O Brasil mantém um modelo de polícia híbrido no qual convivem a polícia investigativa de caráter civil e a polícia ostensiva de caráter militar. A militarização e 
as frequentes intervenções militares na segurança apontam para a persistência dos casos de violência, de intolerância à diversidade e à pluralidade, bem como de resistência ao controle civil (Fleury, 2012; Zaverucha, 2005).

\section{Persistência da violência policial no Brasil}

\section{O caso de São Paulo}

A letalidade em ações policiais ganhou destaque nacional e internacional no contexto dos anos 1990, com o massacre do Carandiru, as chacinas da Candelária, do Vigário Geral e de Eldorado dos Carajás. Mas, o que preocupa a pesquisa acadêmica é a letalidade perpetrada cotidianamente como justificativa ao combate ao crime. O uso da força refere-se a um leque de ações à disposição da polícia: presença física, ordens verbais, uso de armas não letais e, no limite, o uso da arma de fogo. A linha que separa o uso justificado do uso excessivo da força é tênue e precisa ser permanentemente problematizada. As pesquisas sobre uso da força no Brasil vêm apontando a persistência de um alto padrão de letalidade, considerando os três métodos de aferição: não correlação entre mortos e feridos; desproporção entre mortes de policiais e não policiais; falta de correlação entre letalidade pela polícia e os homicídios. (Cano, 1997, 2002; Carneiro \& Oliveira Jr, 2002; Lima, 2011; Mesquita Neto, 1999;)5. A força letal, neste

Tabela 1 Letalidade e vitimização nas ações da polícia. Estado de São Paulo. PM e PC. 2000-2017

\begin{tabular}{|c|c|c|c|}
\hline $\begin{array}{c}\text { Ano } \\
\text { das Ocorrências }\end{array}$ & $\begin{array}{l}\text { Policiais mortos } \\
\text { (PM e PC) }\end{array}$ & $\begin{array}{l}\text { Não-policiais } \\
\text { mortos }\end{array}$ & $\begin{array}{c}\text { Razão entre mortes } \\
\text { de policiais e não policiais }\end{array}$ \\
\hline 2000 & 228 & 837 & 3,67 \\
\hline 2001 & 149 & 703 & 4,71 \\
\hline 2002 & 124 & 994 & 8,01 \\
\hline 2003 & 144 & 826 & 5,76 \\
\hline 2004 & 126 & 975 & 7,73 \\
\hline 2005 & 125 & 739 & 5,92 \\
\hline 2006 & 88 & $469^{(a)}$ & 5,32 \\
\hline 2007 & 36 & $438^{(a)}$ & 12,16 \\
\hline 2008 & 22 & $431^{(a)}$ & 19,59 \\
\hline 2009 & 22 & $549^{(a)}$ & 24,95 \\
\hline 2010 & 25 & $517^{(a)}$ & 20,68 \\
\hline 2011 & 43 & 481 & 11,18 \\
\hline 2012 & 87 & 582 & 6,69 \\
\hline 2013 & 66 & 369 & 5,59 \\
\hline 2014 & 17 & 727 & 42,76 \\
\hline 2015 & 16 & 648 & 40,50 \\
\hline 2016 & 24 & 856 & 35,66 \\
\hline $2017^{(b)}$ & 45 & 927 & 20,6 \\
\hline Total & 3311 & 18.985 & 5,73 \\
\hline
\end{tabular}

\footnotetext{
${ }^{(a)}$ Entre 2006 e 2010, os dados oficiais não apresentam as mortes de policiais fora de serviço.

${ }^{(b)}$ Para o ano de 2017, ver OESP, 25 de janeiro de $2018^{6}$ e Uol Notícias, 22 de abril de $2018^{7}$.

Fonte: Secretaria de Segurança Pública/SP, NEV-USP e Lima (2011).
} 
sentido, é um instrumento fortemente legitimado pela instituição policial e pela opinião pública. Em síntese, a ação letal é um método recorrente empregado pela polícia brasileira, mais do que em outros países (Chevigny, 1995, Lima, 2011; Mesquita Neto, 1999).

Os números da tabela 1 apontam para a tendência de manutenção das mortes de não policiais e para uma redução do número de policiais mortos. Enfim, a letalidade de não policiais não acompanha a redução das mortes de policiais e nem a redução das taxas de crimes violentos no Estado. ${ }^{8}$ E desde 2014, a letalidade em ações policiais vem atingindo os altos patamares do começo dos anos 2000. As pesquisas apontam que as mortes de policiais ocorrem em sua maioria em situação de folga do trabalho. Enquanto a morte de não policiais ocorre quando o policial está em serviço. A estimativa mais confiável aponta que $2 / 3$ dos policiais mortos estavam em folga. ${ }^{9}$

Pesquisa da Ouvidoria de Polícia de São Paulo (OPSP) analisou os dados da letalidade na cidade de São Paulo para o ano de 1999. A pesquisa mostrou que o padrão de letalidade de não policiais aponta para situações de execuções sumárias. A legítima defesa ou o estrito cumprimento de dever legal são as justificativas usadas para as mortes. Em geral, a descrição dos fatos nos boletins de ocorrência aponta para a morte de não policiais como decorrência de confronto (Ouvidoria de Polícia do Estado de São Paulo, 2000). Do total de processos-crime abertos em 1999, $45 \%$ não chegaram a ser apreciados pelo Ministério Público e pelo Poder Judiciário. Dos inquéritos instaurados pela Polícia Civil, apenas 50,8\% chegam à fase da instrução e desse total, $44,4 \%$ foram arquivados. ${ }^{10}$

Segundo a Human Rights Watch (2009), entre 2004 e 2008, foram mortas 305 pessoas pelo Batalhão de Choque, durante confrontos com resistência à prisão. No mesmo período, 20 pessoas foram feridas e um único policial foi morto. No mês de maio, nos ataques do Primeiro Comando da Capital (PCC), foram mortos 47 não policiais pela Rota. Neste ano as forças de segurança do Estado de São Paulo (ESP) sofreram atentados coordenados do interior das penitenciárias paulistas pelo PCC. Durante os dias 12 e 21 de maio foram 63 ataques a delegacias, carros e bases da PM, Polícia Civil (PC) e do Corpo de Bombeiros. Os ataques resultaram em 59 agentes de segurança e 505 não policiais mortos, sendo que 118 foram mortos em confronto com a polícia. ${ }^{11}$ Esses números não foram incorporados aos relatórios trimestrais divulgados pela SSP-SP.

\section{O caso do Rio de Janeiro}

Em 2017, segundo o Instituto Público de Segurança do Rio de Janeiro, foram assassinados na área metropolitana 4.432 pessoas. Segundo levantamento do Instituto 
Datafolha e Fórum Público de Segurança, 76\% da população do Rio de Janeiro apoia a intervenção federal, $92 \%$ tem medo de ser morto em um assalto, $87 \%$ tem medo de ser assassinado, e $75 \%$ das pessoas, ou seja, quase 4 milhões de pessoas declararam que ouvem pelo menos um tiroteio nos bairros.

Em fevereiro de 2018, sob uma vasta campanha de mídia sobre a opinião pública, o presidente brasileiro Michel Temer decretou a intervenção federal na segurança pública no Rio de Janeiro, através do Decreto Presidencial n ${ }^{\circ} 9.288$. A resposta federal tornou possível delegar o controle total de todos os atores de segurança às Forças Armadas, e mais de 3.000 soldados chegaram ao Rio. É importante destacar que as ações de intervenção militar na área de segurança pública não são um fenômeno extemporâneo, mas sim recorrente. As Forças Aramadas são usualmente chamadas para desempenhar ações tanto de segurança pública como outras ações subsidiárias (figura 1).

Nesse cenário, a letalidade de agentes de segurança do Estado indica de maneira inequívoca o caráter da política de enfrentamento e do resultado imediato desta agenda, isto é, a partir de 2015, podemos ver claramente uma inflexão ascendente nos índices de letalidade dos agentes do Estado.

Esse contexto público de (in)segurança abriu uma brecha para a política de segurança "mano dura" e as eleições políticas de 2018 ratificaram esse apoio em diversos principais Estados do Brasil, como Rio de Janeiro, São Paulo, Minas Gerais, Rio Grande do Sul e Santa Catarina, a eleição de Jair Bolsonaro como presidente do Brasil. Um ponto que merece atenção é que esse processo eleitoral de apoio a uma agenda de segurança pública voltada para um enfrentamento de extermínio não foi exclusividade apenas no Brasil, mas também em outros governos latino-americanos democraticamente eleitos que adotaram estratégias similares de "mano dura" nos últimos anos.

Essa dimensão contextual e regional das escolhas políticas indica que a criminalidade se define no contexto da ação e na percepção dos atores que sofrem a violência (Rodgers \& Baird, 2016). A violência e a criminalidade estão em uma perspectiva relacional e devem ser consideradas em função dos novos atores envolvidos e dos contextos políticos. Se durante os anos de guerra fria entre o mundo capitalista e o mundo socialista, este último servia como o "inimigo por excelência" numa estrutura ampla de securitização (Buzzan, Waever \& Wilde, 1998) das relações políticas nacionais e internacionais, esta posição seria ocupada a partir dos anos 1990 por aquilo que se convencionou denominar como atores não estatais violentos (violent non-state actors -VNSAs). Nesse sentido a questão política e econômica reorientou os atores políticos, (Kruijt \& Koonings, 1999) e o que emergiu no campo dos conflitos intraestatais e interestatais foi uma inflexão dos conflitos 


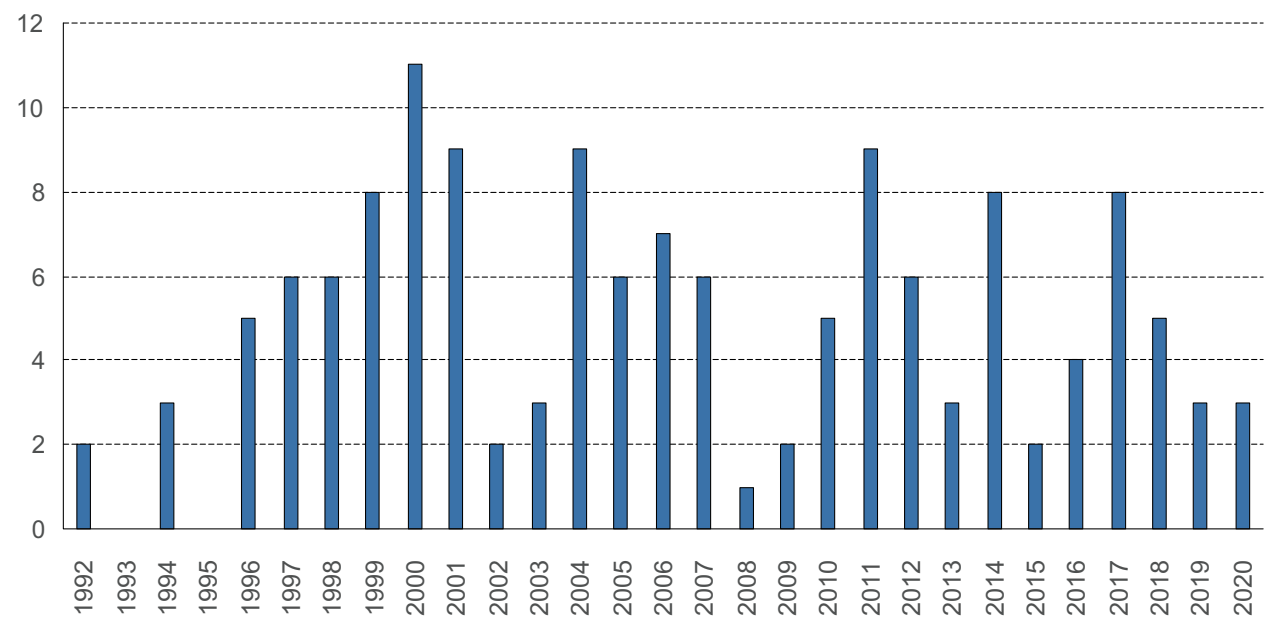

Figura 1 Ações de Garantia da Lei e da Ordem (1992-2020)

Fonte: Ministério da Defesa, $2020^{12}$.

ideológicos sobre a ontologia dos regimes políticos para uma versão mais imediata de violência, isto é, aquela vinculada ao crime e a delinquência.

O caso do Rio de Janeiro oferece para este estudo um exemplo interessante de pesquisa, pois ao mesmo tempo em que se identificam três atores centrais, a saber: Comando Vermelho (CV), Amigos dos Amigos (ADA) e o Terceiro Comando Puro (TCP), se pode afirmar que há um quarto ator de relevância ausente, as milícias. O embate entre as milícias que possuem laços com órgãos estatais e inclusive representatividade política junto as câmaras municipais e estaduais e o tráfico são um elemento de complexidade que se soma ao modelo conhecido de enfrentamento entre facções rivais do tráfico de drogas.

As milícias, no Rio de Janeiro, na origem, estão vinculadas aos grupos de extermínio, dos anos 1960, sendo o mais notório o Esquadrão da Morte, do detetive Le Coq, sendo que neste período foi criado a Scuderie Le Coq, composta pelos autodenominados "Homens de Ouro" da polícia do Rio de Janeiro, como afirma Misse (2011). Deste grupo, provém o termo comumente utilizado tanto no senso comum como mote de campanha política, a saber: "bandido bom é bandido morto".

A polícia mineira seria uma variante dos esquadrões da morte dos anos 1960/1970 que surge a partir dos anos 1980 e tem sua origem em policiais e ex-policiais que buscavam oferecer segurança a pequenos comércios e localidades mais distantes do centro da cidade do Rio de Janeiro. O termo polícia mineira 
se origina de grupos de policiais de Minas Gerais notórios por suas práticas violentas. A partir dos anos 1990 podemos indicar como um ponto de inflexão ou de aprimoramento das relações econômico/violentas entre as milícias e a população. Segundo Zaluar e Conceição (2007) foi por meio das associações de moradores que um novo arranjo foi sendo estabelecido, ou seja, a proteção não se restringia aos pequenos negócios, mas também a população das áreas definidas sob a jurisdição destes grupos.

A Liga da Justiça, talvez uma das mais bem-sucedidas organizações desta natureza surge deste modelo organizacional na Zona Oeste do Rio de Janeiro e se expande a partir de então se ramificando e se subdividindo. A localidade de Rio das Pedras na Zona Oeste do Rio de Janeiro ficou conhecida como o epicentro de onde a forma miliciana de controle da violência se expandiu pela cidade do Rio de Janeiro.

A partir de entrevista ao jornal O Globo, o Procurador Luiz Antônio Ayres expõe a complexidade da questão da segurança pública e das organizações milicianas. Segundo dados do Ministério Público do Rio de Janeiro, em torno de 26 bairros da cidade estariam sob o controle de grupos milicianos, isto representa que $16,5 \%$ do total de bairros da cidade do Rio de Janeiro (160 bairros) estariam sob o controle destas organizações com aproximadamente um total de 2.2 milhões de pessoas.

A dispersão se dá de maneira planejada segundo o procurador e tem por objetivo alcançar a Zona Norte do Rio de Janeiro, sendo que no atual momento o ponto estratégico de embate entre traficantes e milicianos se dá na Cidade de Deus, onde tem ocorrido uma série de confrontos e mortes decorrentes destas ações e das ações policiais desde 2018.

Ao analisarmos a incidência em três das sete regiões integradas de segurança (RISP) do Rio de Janeiro, percebemos que a partir do ano de 2018 com a chegada de Wilson Witzel ao governo do Estado do Rio de Janeiro, os números da letalidade policial sobem de maneira significativa, posto que a partir de 2018 se intensifica uma política de enfrentamento, tendo o governador dado declarações que reafirmaram essa assertiva, tal como "tiro na cabecinha" numa alusão ao posicionamento de snipers próximos as comunidades da cidade do Rio de Janeiro.

A questão da criminalidade, da segurança pública e das políticas relativas ao controle e diminuição da violência encontram no Rio de Janeiro um círculo de erro e repetição, com pouca margem para opções de novas agendas em termos de segurança pública. Ao longo dos últimos 30 anos a política de segurança pública tem se sustentado na lógica do enfretamento, a qual desconsidera aparentemente fatos auto evidentes, tais como: o ilícito vinculado ao crime organizado e a violência não é exclusividade de uma parcela da população a qual é segregada, socialmente, economicamente e racialmente. 


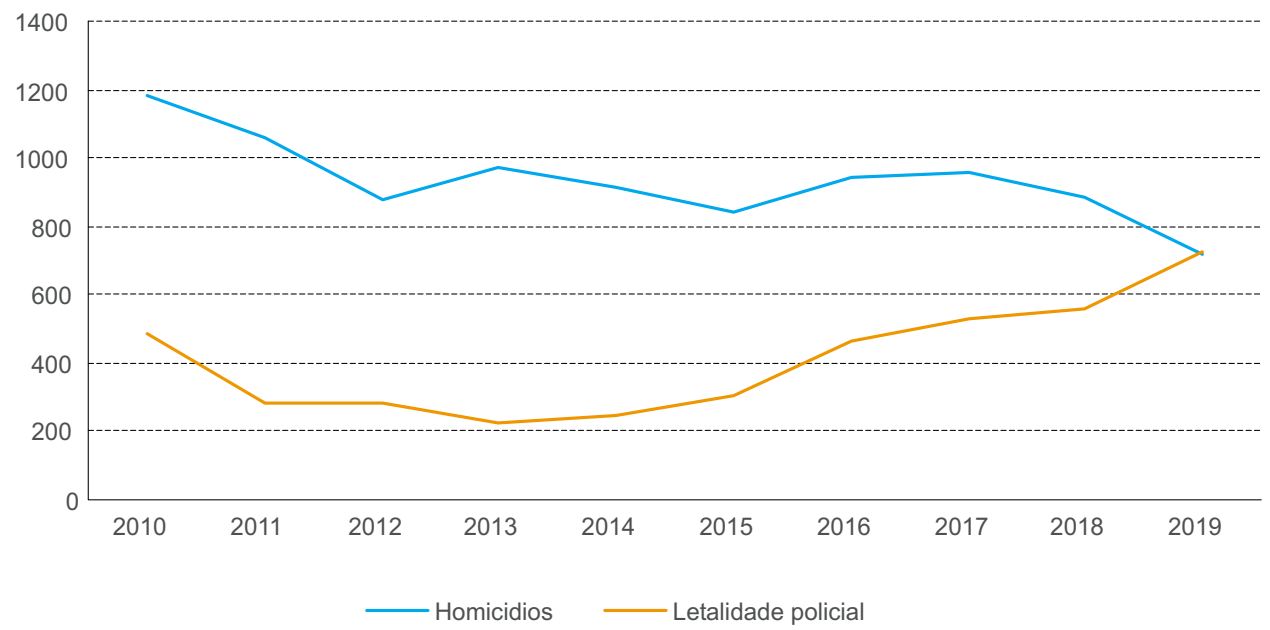

Figura 2 Comparativo entre letalidade policial e taxa de homicídio na cidade do Rio de Janeiro (2010-2019) Fonte: Instituto de Segurança Pública (ISP).

Segundo estudo realizado pelo Centro de Pesquisas do Ministério Público do Rio de Janeiro (CENPE/MPRJ) não é possível estabelecer uma correlação direta entre a aplicação de uma política de segurança pública pautada no enfretamento com maior letalidade por parte dos agentes do Estado e, como efeito causal tendo a diminuição da taxa de homicídios, ainda que a letalidade tenha atingido até julho de 2019, 1.256 pessoas contra, 1.075 do período anterior. Esta afirmação se traduz pela análise detalhada dos dados relativos à queda da taxa de homicídios, com a letalidade dos agentes do Estado projetadas sobre as áreas integradas de segurança pública do Rio de Janeiro.

Segundo o relatório de um total de 39 Áreas de Segurança Integrada de Segurança Pública (AISP), quatro delas respondem por $42 \%$ da queda verificada na taxa de homicídios em todo o Estado do Rio de Janeiro. A AISP de Queimados (24) indicou uma queda de 2.5 pontos percentuais na taxa de homicídios dolosos e um aumento de 9.4 pontos percentuais, Nova Iguaçu (20), São Gonçalo (7), Rio das Ostras (32) e Angra dos Reis (33) apresentam uma correlação não linear entre letalidade por agentes do Estado e a queda na taxa de homicídios. Destas 5 áreas somente São Gonçalo com um aumento de 13.2 pontos percentuais e Queimados com 9.4 pontos percentuais registraram aumento nas mortes por intervenção de agentes do Estado. Enquanto Nova Iguaçu registrou queda de 20.7 pontos percentuais, Rio das Ostras queda de 10.5 pontos percentuais e Angra dos Reis com queda de 31 pontos percentuais. Por outro lado, a taxa de letalidade em Santa Cruz na Zona Oeste do 
Rio de Janeiro enquanto a taxa de homicídios dolosos caiu 1.2 pontos percentuais, a letalidade por agentes do Estado caiu 90 pontos percentuais.

Através destes dados preliminares, os quais merecem maior tempo de análise, que apontam para o indício de que o êxito da política de enfretamento por extermínio pautada no mote "bandido bom é bandido morto" não encontra amparo nos dados registrados pelo Instituto de Segurança Pública e nem tampouco pela análise desenvolvida pelo Ministério Público do Estado do Rio de Janeiro. Não há uma relação causal geral para que se possa afirmar que a diminuição da taxa de homicídios dolosos no Rio de Janeiro esteja vinculada a um tipo de política pública de segurança estruturada sobre a ideia do puro e simples enfrentamento.

É baseado na premissa de que a sociedade brasileira desenvolveu um sistema legal, punitivo e militarizado que reforça a distribuição desigual de poder. No Rio de Janeiro, em particular, portanto, sustentamos que desde a segunda metade dos anos 90, esta "política do confronto" ainda é hegemônica e observamos, então, no cenário político atual que houve um aumento da letalidade do Estado, em face de uma política genocida em que as "vidas indignas", passíveis de serem "matáveis", até agosto de 2019, os primeiros oito meses do atual governo, excedem o número de 1.200 pessoas mortas. Há ainda uma intensa produção de execuções, assassinatos e homicídios, quase todos "em nome" da "guerra às drogas".

Assim sendo, no Rio de Janeiro, há algumas décadas, pode-se observar o exercício punitivo que se articula à política de extermínio, de genocídio, portanto, que atinge os segmentos percebidos como "indignos de vida" (Zaccone, 2015), considerados também como "descartáveis" (Mbembe, 2018). É nesta dialética entre estado de direito e estado policial/penal (Zaffaroni, 2007) que procuramos compreender o "poder de ditar quem pode viver e quem deve morrer" (Mbembe, 2018).

\section{Conclusão}

Nas sociedades democráticas, as polícias militarizadas crescem significativamente em efetivo, recursos, custos e capacidade de intervenção. As modernas democracias planetárias estão dando mostras de que não podem abrir mão de suas polícias, e com isto, reforçam suas estratégias securitárias, de gestão de riscos ao mesmo tempo em que militarizam a relação com imigrantes, refugiados e suspeitos de terrorismo, dentro de uma lógica de estado de exceção permanente.

Nesse sentido defendemos o argumento de que o estado de direito produz as suas exceções permanentes; em outras palavras, estado de direito e estado de exceção não são antagônicos, e isso sinaliza, de forma bem concreta, para a complexa 
relação existente entre legalidades e ilegalidades. Vale dizer, também que o estado de direito fabrica em larga escala as suas próprias ilegalidades.

Desta forma, enquanto possibilidade interpretativa, podemos tentar compreender como há ainda todo um dispositivo punitivo e militarizado, jurídico também, que produz incessantemente "vidas indignas", "vidas matáveis", e em nome de uma pretensa "guerra ao inimigo", a questão da "política criminal com derramamento de sangue" (Batista, 1998) no que tange à guerra às drogas, aumenta de forma exponencial a letalidade da polícia e do Estado.

Os mecanismos de controle sobre as ações policiais encontram-se travados pelo montante securitário e expõem seus limites quando o assunto é redução do número de mortes pela polícia. Estamos no dilema entre um aparato policial civil que se submeta às regras do jogo democrático e estratégias ilegais de controle de fronteiras e dos riscos do mundo globalizado.

Pensando mais especificamente sobre o Brasil a partir da experiência desta pesquisa, é possível estabelecer controles e aprimorar os já existentes? Os dados analisados neste artigo mostram que a letalidade de não policiais não é aleatória.

Os números demonstram que o padrão de alta letalidade é mantido, sugerindo que a violência policial é uma ferramenta a ser acessada pelos governos e suas polícias. Temos que pensar nestas questões e apontar agendas de pesquisa que possam jogar um pouco de luz sobre um futuro que, por enquanto, parece incerto.

Por fim, podemos sustentar que a letalidade policial não se encontra afastada da letalidade do Estado, ou seja, se há letalidade policial, há também a letalidade do Estado. Essas letalidades, na verdade, se imbricam e insistem na formulação e execução de políticas genocidas, de confronto, extermínio e que acabam por fomentar milícias.

\section{Notas}

Por decisão pessoal, os autores do texto escrevem segundo o novo acordo ortográfico.

1 Consultar, documento do Ministério da Justiça, de 2010, O que é o Pronasci. Disponível em https://www.senado.gov.br/comissoes/CE/AP/PDE/AP_08_MinisterioJustica.pdf

2 As ações para "Garantia da Lei e da Ordem" são previstas no $\operatorname{Art}^{\circ} 142^{\circ}$ da Constituição (1988) e foram regulamentadas pela Lei Complementar no 97 (1999) e pelo Decreto Presidencial no 3.897 (2001). Essas ações preveem a utilização das Forças Armadas em situações em que houver o entendimento que as forças policiais locais não são mais capazes de lidar com uma determinada crise; no entanto, as GLO tem se tornado usuais e foram a base da intervenção militar federal no Estado do Rio de Janeiro, em 2018.

3 Mesmo o Pronasci teve limites claros, pois ao articular políticas institucionais e repressivas com políticas sociais e preventivas, enfatizou que as últimas formariam a 
diretriz norteadora do programa. Entretanto, o maior dispêndio de verbas entre 2008 e 2013 foi para políticas institucionais, corporativas, ligadas a treinamento, aperfeiçoamento das instituições de segurança, reformas e construção de presídios, com $73 \%$,e de apenas $24 \%$ para as políticas sociais e preventivas, de assistência social e suporte às vítimas de violência doméstica e urbana (Almeida, 2014, p. 77). Ver

https://g1.globo.com/rj/rio-de-janeiro/noticia/forcas-armadas-ja-atuaram-na-segura nca-do-rj-em-outras-situacoes-veja-quais.ghtml

5 Evidentemente, outros indicadores podem ser usados para a discussão sobre o uso justificado da violência letal pela polícia: quantidade de tiros identificados nos corpos das vítimas, posição e ângulo dos tiros, disposição da cena do crime, correlação entre o número de policiais e de criminosos presentes à ação, local e horário, antecedentes criminais das vítimas, etc.

6 Disponível em https:/ / sao-paulo.estadao.com.br/noticias/geral,letalidade-policial-em-sp-e-a-ma ior-desde-2001-homicidios-caem,70002164430.

7 Disponível em https://noticias.uol.com.br/cotidiano/ultimas-noticias/2018/04/22/em-10-anos77-dos-pms-mortos-em-sp-nao-estavam-em-servico.htm

8 Os dados oficiais devem ser comparados com mortes violentas nas periferias e nas regiões metropolitanas das principais capitais do Brasil, na medida em que as mortes violentas contam com a participação de policiais (Macedo, 2015).

9 Cano (1997) observou um padrão de letalidade que aponta para execuções sumárias pela polícia do Rio de Janeiro nos anos 1990. Nos anos 2000, os dados apontavam que a cada 05 policiais mortos, entre 2000 e 2006, 04 estavam em folga (Ribeiro, Dias \& Carvalho, 2009, pp. 12-14).

10 Para consultar mais dados sobre São Paulo, ver www.ouvidoria-policia.sp.gov.br.

Pesquisa da UFSCar aponta para a prevalência da letalidade de não-brancos e de jovens, disponível em

http://www.ufscar.br/gevac/wp-content/uploads/Sum\%C3\%A1rio-Executivo_FINA L_01.04.2014.pdf.

11 Segundo a matéria de capa do jornal O Estado de São Paulo: “Dos 564 mortos durante os ataques do PCC em maio de 2006, 505 eram civis." (Souza \& Jozino, 2009).

12 Disponível em https://www.gov.br/defesa/pt-br/assuntos/exercicios-e-operacoes/garantia-dalei-e-da-ordem

\section{Referências}

Adorno, S. (2002). Monopólio estatal da violência na sociedade brasileira contemporânea. In S. Miceli (Org.), O que ler na ciência social brasileira (1970-2002) (pp. 267-307). São Paulo: Editora Sumaré. 
Aguilar, S. L. C. (2012). Segurança pública e as operações de construção da paz pós-conflitos armados. Estudos de Sociologia, 17(33), 429-445.

Almeida, F. B. (2014). Orçamento e segurança pública: um estudo de caso do Programa Nacional de Segurança Pública com Cidadania (PRONASCI) (Dissertação de Mestrado, Universidade de Brasília, Brasília, Brasil).

Batista, N. (1998). Política criminal com derramamento de sangue. Discursos Sediciosos: crime, direito e sociedade, 5/6, 237-262.

Battibugli, T. (2007). Democracia e segurança Pública em São Paulo (1946-1964) (Tese de Doutoramento, Universidade de São Paulo, São Paulo, Brasil).

Bayley, D. (2001). Padrões de policiamento. São Paulo: Editora da Universidade de São Paulo.

Bayley, D. (2006). Changing the guard. Developing democratic police abroad. Oxford: Oxford University Press.

Belli, B. (2004). Tolerância zero e democracia no Brasil: visões da segurança pública na década de 90. São Paulo: Perspectiva.

Bicudo, H. (2000). A unificação das polícias no Brasil. Estudos Avançados, 14(40), 91-106.

Bittner, E. (2003). Aspectos do trabalho policial. São Paulo: Editora da Universidade de São Paulo.

Borges, N. (2003). A doutrina de segurança nacional e os governos militares. In: J. Ferreira, \& L. de A. N. Delgado (Orgs.), O Brasil Republicano: o tempo da ditadura regime militar e movimentos sociais em fins do século XX (Vol. 4, pp. 462-466). Rio de Janeiro: Civilização Brasileira.

Buzzan, B., Weaver, O., \& Wilde, J. (1998). Security: A new framework for analysis. London: Liener Publishers.

Caldeira, T. P. do R. (2001). Cidade de muros: crime, segregação e cidadania em São Paulo. São Paulo: Editora da Universidade de São Paulo e Editora 34.

Cano, I. (1997). Letalidade da ação policial no Rio de Janeiro. Rio de Janeiro: Instituto de Estudos da Religião.

Cano, I. (2002). O controle da atividade policial: o uso da força letal. In B. D. Mariano (Org.), Primeira Conferência Internacional sobre controle externo da polícia (pp. 173-195). Osasco: JM Edições.

Carneiro, L. P., \& Oliveira Jr., E. (2002). Estratégias de controle da violência policial. Notas de pesquisa. In J. Zaverucha, \& M. R. Negreiros Barros (Orgs.), Políticas de segurança pública: dimensão da formação e impactos sociais (pp. 91-110). Recife: Fundação Joaquim Nabuco.

Chevigny, P. (1995). The edge of the knife: police violence in the Americas. Nova Iorque: New York Press.

Constituição da República Federativa do Brasil, de 5 de outubro de 1988. Diário Oficial da União.

Cristino, F. da R. (2008). Segurança pública e democracia: um novo paradigma. Âmbito Jurídico, (57). Disponível em

https://ambitojuridico.com.br/cadernos/direito-penal/seguranca-publica-e-dem ocracia-um-novo-paradigma/ 
Decreto $\mathrm{n}^{\circ} 3.897$, de 24 de agosto de 2001. Fixa as diretrizes para o emprego das Forças Armadas na garantia da lei e da ordem, e dá outras providências. Diário Oficial da União, seção 1, 164, 66.

Decreto $n^{\circ}$ 9.288, de 16 de fevereiro de 2018. Decreta intervenção federal no Estado do Rio de Janeiro com o objetivo de pôr termo ao grave comprometimento da ordem pública. Diário Oficial da União, seção 1, edição extra, 1.

Dieu, F. (1993). Gendarmerie et modernité. Paris: Montchrestien.

Ericson, R. V., \& Haggerty, K. D. (1997). Policing the risk society. Toronto: University of Toronto Press.

Estevam, D. de O. (2010). A contínua descontinuidade administrativa e de políticas públicas. Anais do II Seminário de Ciências Sociais Aplicadas, 2(2). Disponível em http://periodicos.unesc.net/seminariocsa/issue/archive

Fleury, S. (2012). Militarização do social como estratégia de integração: o caso da UPP do Santa Marta. Sociologias, 14(30), 194-222. Disponível em https://www.scielo.br/scielo.php?pid=S1517-45222012000200007\&script=sci_arttext

Fontoura, N., Rivero, P. S., \& Rodrigues, R. I. (2009). Segurança pública na Constituição Federal de 1988: continuidades e perspectivas. Boletim de Políticas Sociais: Acompanhamento e Análise. Vinte Anos de Constituição Federal, 3(17), 135- 198.

Gusso, R. B. (2013). Eu previno, tu reprimes. Uma análise da política criminal ofertada pelo Pronasci por meio do programa Protejo, Curitiba-PR (Tese de Doutoramento, Universidade Federal do Paraná, Curitiba, Brasil).

Human Rights Watch. (2009). Força Letal Violência Policial e Segurança Pública no Rio de Janeiro e em São Paulo. EUA: HRW. Disponível em https://www.hrw.org/pt/report/2009/12/08/256012

Kruijt, D., \& Koonings, K. (2002). Fuerzas Armadas y política en América Latina: perspectivas futuras. Iberoamericana, 2(8), 7-22.

Lei $\mathrm{n}^{\circ} 13.260$, de 16 de março de 2016. Regulamenta o disposto no inciso XLIII do art. $5^{\circ}$ da Constituição Federal, disciplinando o terrorismo, tratando de disposições investigatórias e processuais e reformulando o conceito de organização terrorista. Diário Oficial da União, seção 1, edição extra, 1.

Lei complementar $n^{\circ} 97$, de 9 de junho de 1999. Dispõe sobre as normas gerais para a organização, o preparo e o emprego das Forças Armadas. Diário Oficial da República Federativa do Brasil, edição extra.

Lima, R. K. de (1989). Cultura jurídica e práticas policiais: A tradição inquisitorial. Revista Brasileira de Ciências Sociais, 4(10), 65-84.

Lima, R. K. de (1995). A polícia da cidade do Rio de Janeiro: seus dilemas e paradoxos. Rio de Janeiro: editora Forense.

Lima, J. M. M. de. (2011). Democracia e accountability. Violência policial e prática de controle sobre a Polícia Militar do Estado de São Paulo (Dissertação de Mestrado, Universidade Estadual Paulista, Marília, Brasil). 
100 Luís Antônio Francisco de Souza, Carlos Henrique Aguiar Serra,Marcial A. Garcia Suarez e Gabriel de Sousa Romero

Macedo, H. de L. dos S. (2015). Confrontos de rota: a intervenção policial com "resultado morte" no Estado de São Paulo (Dissertação de Mestrado, Universidade Federal de São Carlos, São Carlos, Brasil).

Mbembe, A. (2018). Necropolítica. São Paulo: N-1edições.

Mesquita Neto, P. (1999). Violência policial no Brasil: abordagens teóricas e práticas de controle. In D. C. Pandolfi, L. Piquet, \& J. M. Carvalho (Orgs.), Cidadania, justiça e violência (pp. 129-148). Rio de Janeiro: editora da Fundação Getúlio Vargas.

Mingardi, G. (1992). Tiras, gansos e trutas. Cotidiano e reforma na polícia civil. São Paulo: Escrita Editorial.

Misse, M. (2011). "Autos de resistência": uma análise dos homicídios cometidos por policiais na cidade do Rio de Janeiro (2001-2011). Rio de Janeiro: editora da Universidade Federal do Rio de Janeiro.

Moraes, B. B. (Org.) (1996). O papel da polícia no regime democrático. São Paulo: Mageart.

Ouvidoria de Polícia do Estado de São Paulo. (2000). Pesquisa sobre o uso da força letal por policiais de São Paulo no ano 2000. São Paulo: editora do Governo do Estado de São Paulo.

Pinheiro, P. S. (1991). Autoritarismo e transição. Tempo Social. Revista de Sociologia da USP, (9), 45-56.

Ribeiro, C., Dias, R., \& Carvalho, S. (2009). Políticas e práticas na construção de uma política de segurança. O caso do governo Sérgio Cabral Filho (2007-2009). In Justiça Global (Org.), Segurança, tráfico e milícias no Rio de Janeiro (pp. 6-16). Rio de Janeiro: Fundação Heinrich Böll.

Rodgers, D., \& Baird, A. (2016). Entender a las pandillas de América Latina: una revisión de la literatura. Estudios Socio-Jurídicos, 18(1), 13-53.

Sento-Sé, J. T. (Org.), (2005). Prevenção da violência: o papel das cidades. Rio de Janeiro: Civilização Brasileira.

Soares, L. E. (2000). Meu casaco de general: quinhentos dias no front da segurança pública do Rio de Janeiro. São Paulo: Companhia das Letras.

Souza, B., \& Jozino, J. (2009, 27 de junho). Dos 564 mortos durante os ataques do PCC em maio de 2006, 505 eram civis. O Estado de São Paulo. Disponível em https:/ / brasil.estadao.com.br/noticias/geral,dos-564-mortos-durante-os-ataquesdo-pcc-em-maio-de-2006-505-eram-civis,393894

Souza, L. A. F. de (2012, 7 de março). A militarização da segurança. Le Monde Diplomatique Brasil. Disponível em http:/ / diplomatique.org.br/a-militarizacao-da-seguranca/

Souza, L. A. F. de, \& Battibugli, T. (2014). Os desafios da reforma da polícia no Brasil. Revista Paranaense de Desenvolvimento, 35(126), 49-60.

Souza, L. A. F. de, Serra, C. H. A., \& Battibugli, T. (2019). Perspectives on the militarization of public security in contemporary Brazil. Oñati Socio-Legal Series, 9(6), 1118-1133.

Stepan, A. (1975). Os militares na politica. Rio de Janeiro: Arte Nova.

Stephan, C. (2016). A Doutrina da Segurança Nacional de Contenção na Guerra Fria: fatores que contribuíram para a participação dos militares na política brasileira (1947- 1969). Conjuntura Global, 5(3), 537-565. 
Waddington, P. A. J. (1999). Policing citizens: authority and rights. London: UCL Press.

Zaccone, O. (2015). Indignos de vida: a forma jurídica da política de extermínio de inimigos na cidade do Rio de Janeiro. Rio de Janeiro: Revan.

Zaffaroni, E. R. (2007). O inimigo no direito penal. Rio de Janeiro: Revan.

Zaluar, A., \& Conceição, I. S. (2007). Favelas sob o controle das Milícias no Rio de Janeiro: Que paz? São Paulo em Perspectiva, 21(2), 89-101.

Zaverucha, J. (2005). FHC, forças armadas e polícia: entre o autoritarismo e a democracia, 1999-2002. Rio de Janeiro: editora Record.

Zaverucha, J. (2010). A doutrina da garantia da lei e da ordem e o crescente envolvimento das Forças Armadas. In R. K. Lima, L. Eilbaum, \& L. Pires, (Orgs.), Conflitos, direitos e moralidades em perspectiva comparada (Vol. 2, pp. 11-22). Rio de Janeiro, Garamond.

Data de submissão: 06/04/2020 | Data de aceitação: 26/10/2020 